\title{
The kinematic approach to edge-chipping in rotary ultrasonic machining of $\mathrm{Al}_{2} \mathrm{O}_{3}$
}

\author{
Marcel Kuruc ${ }^{1^{*}}$, Marek Zvončan ${ }^{2}$, Jozef Peterka ${ }^{1}$ \\ ${ }^{1}$ Slovak University of Technology, Faculty of Materials Science and Technology, Institute of \\ Production Technologies, Bottova 25, 91724 Trnava, Slovakia \\ ${ }^{2}$ BOGE Elastmetall Slovakia a.s., Product development, Strojárenská 5, 291702 Trnava, Slovakia
}

\begin{abstract}
Rotary ultrasonic machining (RUM) is useful in the machining of difficult-to-cut materials such as $\mathrm{Al}_{2} \mathrm{O}_{3}$. However, the edge-chipping occurs in the machined surface because of the brittleness of ceramics. The origin of edge-chipping is clear in general and several methods to its reduction have been published, briefly described in the article. The article brings new, kinematics based view on the edge-chipping origin and a method of its reduction. Theoretical equations were deduced based on the grit's trajectory characterized by machining variables of the processes. The equations have been employed in a full factorial experiment and experimental results fit the theoretical assumption satisfyingly. The edgechipping was reduced by supposed method significantly.
\end{abstract}

\section{Introduction}

Edge-chipping is breaking off the edge of the machined material when a through hole is machining. This effect is typical for hard and brittle materials due to their mechanical properties. Brittle failure is typical for material removal mechanism for these materials. When the tool is coming through the workpiece, the edge of the created hole will breaks.

Machining parameters influence on edge-chipping has been reported by Zhichao [1]. The influence of spindle speed, feed rate and ultrasonic power is reported according to the experimental results. Li et al. presented a FEM model of edge chipping in Edge-chipping reduction in rotary ultrasonic machining of ceramics [2]. The authors developed a threedimensional finite element analysis (FEA) model to study the effects of three parameters (cutting depth, support length, and pre-tightening load) on the maximum normal stress and von Mises stress in the region where the edge-chipping initiates. Zhang et al. describe a mechanistic model of edge-chipping origin [3]. The calculation is based upon material characteristics of alumina, the maximum compressive strength $\sigma$. $\mathrm{Na}$ Qin described the reduction of edge-chipping by different tool design [4]. Three types of tools were used.

From the literature it follows that edge-chipping can be reduced by optimization of machining parameters, however, cannot be eliminated. Three ways of edge-chipping reduction are proposed in the literature: Underlay the part [2]; invoking opposite force [3]; and the use of specific tool design [4]. However, all these solutions require specific

\footnotetext{
* Corresponding author: marcel.kuruc@stuba.sk
} 
conditions and cannot be applied in general. All the proposed solutions were applied for experimental specimens, however, in the machining of complex parts, their application may be problematic. A lot of parts have a complex shape and cannot be underlaid as it was proposed by $\mathrm{Li}$ et al. [2]. Invoking the opposite force requires uniform distribution of the opposite force which is difficult to reach in the machining of parts with a complex shape, which makes the solution [3] to be not applicable in practice. The solution proposed by Qin [4] is one of the best regarding application possibility in the machining process; however, specially shaped tools are required in this case. The edge-chipping was reported only for the rotary ultrasonic drilling, however, the kinematics of the rotary ultrasonic drilling and its comparison to milling had not been taken into account.

Based on practical knowledge of ultrasonic machining of glass and $\mathrm{ZrO}_{2}, \mathrm{Al}_{2} \mathrm{O}_{3}$ and $\mathrm{SiC}$ ceramics, edge-chipping can be reduced by turning off the ultrasonic generator before the tool pass through the material.

\section{Theoretical background}

In the experiments, two machining technologies were used to create the hole: drilling and milling. The kinematics of material removal in rotary ultrasonic machining (RUM) differs from that for drilling and milling. This difference results from different feed directions for each technology and its relation to the direction of ultrasonic vibrations. The grit's trajectory for rotary ultrasonic drilling and side milling is shown in Fig. 1. The assumption is that the different trajectory of grit has an effect on the edge-chipping.
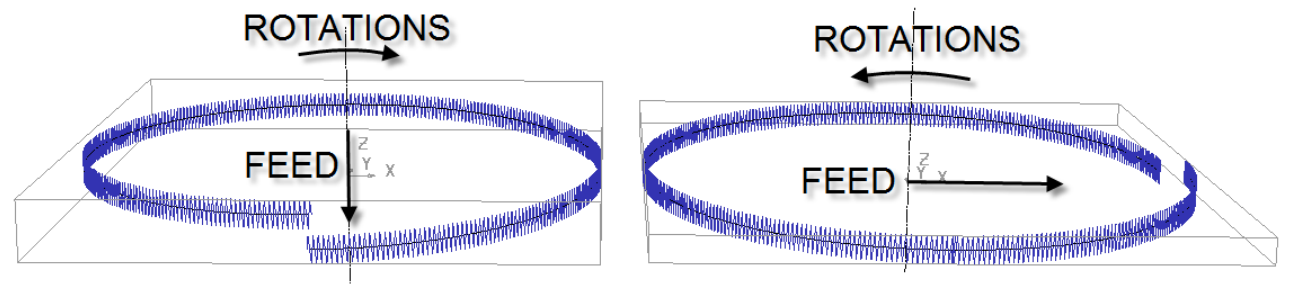

Fig.1. Trajectory of diamond grit for RUM drilling (left) and side milling (right).

The grit's trajectory described by sine curves characterized by frequency and amplitude of vibration and distributed along drive curve characterized by feed and rotations. The trajectory's shape can be modified by changing these parameters. The amplitude of tool vibrations $A_{r}$ can be measured and has certain constant value and the wavelength of tool vibration $L_{r}$ can be calculated from the parameters described above, as shown in Fig. 2.

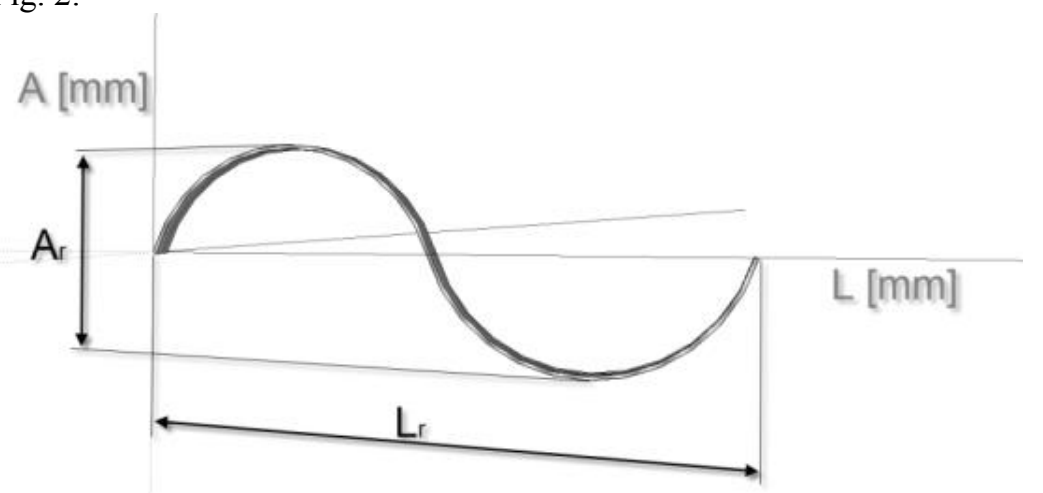


Fig. 2. Grit trajectory's sine curve characteristics.

The wavelength of the tool's vibrations $L_{r}$ than can be calculated according to the tool diameter as follows:

$$
L_{r}=\frac{\pi \cdot D}{N_{r}}=\frac{\pi \cdot D \cdot n}{f \cdot 60}[\mathrm{~mm}]
$$

Where: $\quad \mathrm{L}_{\mathrm{r}} \quad$ is the wavelength

$\mathrm{D}$ is the outer diameter of a tool

$\mathrm{N}_{\mathrm{r}}$ is the number of cycles

$[\mathrm{mm}]$

$\mathrm{n}$ is the frequency of the tool rotations $\left[\mathrm{mim}^{-1}\right]$

$\mathrm{f} \quad$ is the frequency of the tool vibrations $[\mathrm{Hz}]$

From the equation above, the wavelength of a tool can be calculated. Hence the amplitude is constant the shape of grit's trajectory can be modified by changing the rotations and the diameter of a tool. With rising of these parameters the tool vibration's wavelength raises which results to flatter the shape of sine curve i.e. the flatter trajectory of one grit. Therefore for smaller diameter's tools, the higher vibration frequency is needed.

The trajectory's shape affects the machining process into the workpiece and the same parameters result in different machining conditions for drilling and milling. The assumption is, the higher is the angle of grit penetration into the workpiece, the bigger is the edgechipping rate. Taking into account the Eq. 4 and Eq. 5 and using the parameters from Table 1 the real shape of a grit trajectory is shown in Fig. 3. According to the values calculated in the real shape of grit, a trajectory is very flat. The sine curve is nearly not visible in the illustration, therefore the detailed shape of the trajectory's sine curve is depicted.

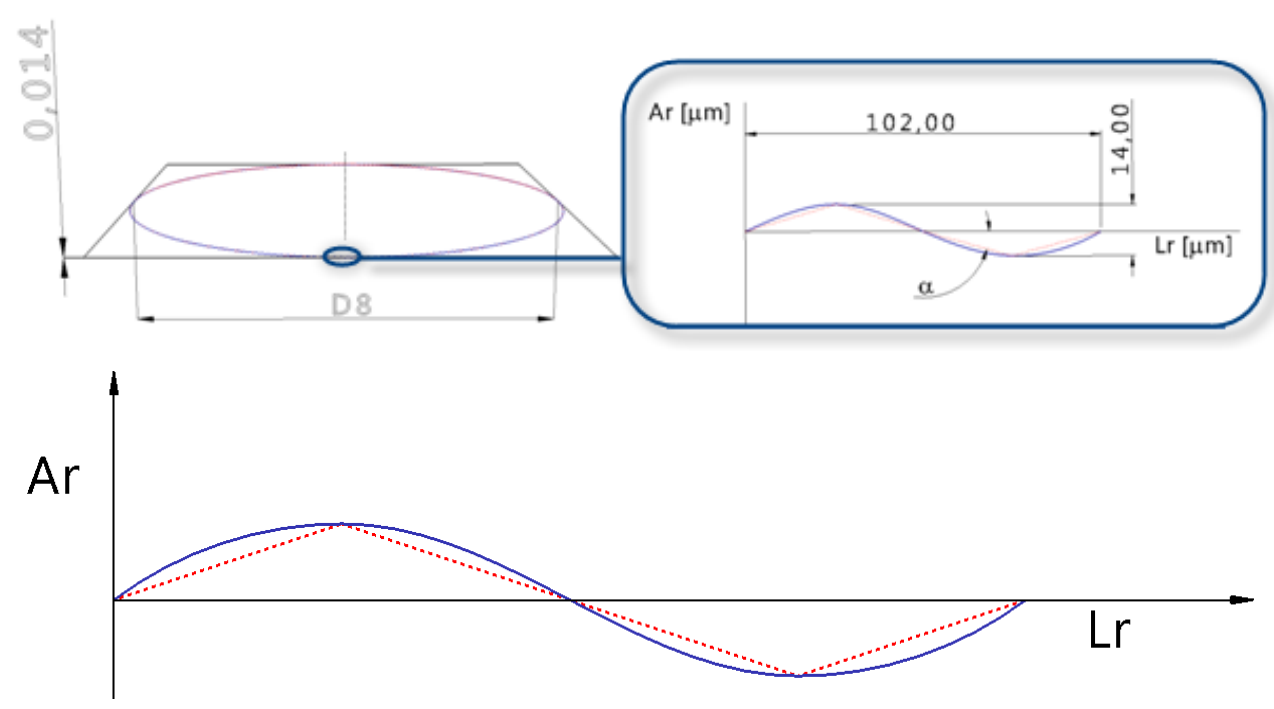

Fig. 3. Real shape of the grit trajectory.

In figure 3, the blue line is the sine curve of grit trajectory, the dotted red line is the approximated linear trajectory of the grain. The approximated trajectory was created to set the mean value of the angle $\alpha$. The angle $\alpha$ is the angle under which the effect of ultrasonic vibration may be calculated into the feed and its effect on cutting force and edge-chipping may be evaluated. The $\alpha$ is calculated as follows: 


$$
\alpha=\operatorname{arctg} \frac{2 \cdot A_{r}}{L_{r}}\left[{ }^{\circ}\right]
$$

The resultant angle of the tool entry into the material $\gamma$ is calculated as a sum of ultrasonic component $(\alpha)$ and conventional component $(\beta)$ :

$$
\gamma=\alpha+\beta=\operatorname{arctg} \frac{2 . A_{r}}{L_{r}}+\beta\left[^{\circ}\right]
$$

where $\beta$ is the angle of grit trajectory without ultrasonic vibrations calculated for drilling as:

$$
\beta=\operatorname{arctg} \frac{v_{f}}{v_{c}}=\operatorname{arctg} \frac{v f}{\pi \cdot D \cdot n}\left[{ }^{\circ}\right]
$$

and for milling as:

$$
\beta=\operatorname{arctg}\left(\frac{v_{f}}{v_{c}} \cdot \frac{a_{p}}{\pi \cdot(D-d)}\right)=\operatorname{arctg} \frac{a_{p} \cdot v f}{\pi^{2} \cdot d \cdot n \cdot(D-d)}\left[{ }^{\circ}\right]
$$

$\begin{array}{llll}\text { Where: } & \mathrm{a}_{\mathrm{p}} & \text { is the depth of cut } & {[\mathrm{mm}]} \\ & \mathrm{v}_{\mathrm{f}} & \text { is the feed rate } & {\left[\mathrm{mm} \cdot \mathrm{min}^{-1}\right]} \\ \mathrm{D} & \text { is the diameter of the machined hole } & {[\mathrm{mm}]} \\ \mathrm{d} & \text { is the diameter of the cutting tool } & {[\mathrm{mm}]} \\ \mathrm{n} & \text { is the frequency of the tool rotations } & {\left[\mathrm{min}^{-1}\right]}\end{array}$

\section{Experimental verification}

Experiments were performed using milling centre DMG Ultrasonic 20 linear. Ultrasonic drill $\varnothing 8 \mathrm{~mm}$ was used for the drilling, and ultrasonic mill Ø $4 \mathrm{~mm}$ was used for the milling of through holes (depth $10 \mathrm{~mm}$ ) with diameter $8 \mathrm{~mm}$ in alumina. Two different spindle speeds and two different feed rates were used as shown in Table 1. Machining parameters for drilling and milling were adjusted as optimal parameters for these technologies, therefore they differ between themselves. Using the same parameters could cause problems during machining (5).

Using the machining parameters introduced in Table 1 in Eq. 4 and Eq. 5 the values of $\beta$ were calculated (see Table 1). This angle achieved low values, especially in terms of milling.

Table 1. The values of angle $\beta$ and $\gamma$.

\begin{tabular}{|c|c|c|c|c|c|c|c|c|}
\hline Technology & \multicolumn{3}{|c|}{ Drilling } & \multicolumn{3}{c|}{ Milling } \\
\hline $\begin{array}{c}\text { Rotations } n \\
{\left[\mathrm{~min}^{-1}\right]}\end{array}$ & \multicolumn{2}{|c|}{5200} & \multicolumn{2}{c|}{5600} & \multicolumn{2}{c|}{6000} & \multicolumn{2}{c|}{7000} \\
\hline $\begin{array}{c}\text { Feed rate } v_{f} \\
{[\mathrm{~mm} / \mathrm{min}]}\end{array}$ & 5 & 15 & 5 & 15 & 500 & 1500 & 500 & 1500 \\
\hline $\begin{array}{c}\text { Angle } \beta \\
{\left[{ }^{\circ}\right]}\end{array}$ & 2.191 & 6.547 & 2.035 & 6.083 & 0,605 & 1.814 & 0.518 & 1.555 \\
\hline $\begin{array}{c}\text { Angle } \gamma \\
{\left[{ }^{\circ}\right]}\end{array}$ & 17.504 & 21.860 & 16.300 & 20.349 & 23.007 & 24.216 & 20.000 & 21.014 \\
\hline
\end{tabular}

In the same way, the values of $L_{r}, N_{r}$ and $\alpha$ for drilling and milling were calculated according to the cutting parameters used in the experiments and the results of calculations are shown in Table 2. 
Table 2. Grit trajectory parameters.

\begin{tabular}{|c|c|c|c|c|c|c|}
\hline \multicolumn{3}{|c|}{ Schott HB-Da.8-0,6-8-35-D107H ER11-1 } & \multicolumn{4}{|c|}{ Schott F-Da.4-1,5-6-15-MES-D107H ER11-1 } \\
\hline $\begin{array}{c}\text { Frequency } \boldsymbol{f} \\
{[\mathrm{Hz}]}\end{array}$ & \multicolumn{2}{|c|}{21300} & $\begin{array}{l}\text { Frequency } \\
{[\mathrm{Hz}]}\end{array}$ & & \multicolumn{2}{|c|}{25900} \\
\hline $\begin{array}{c}\text { Amplitude } A r \\
{[\mu \mathrm{m}]}\end{array}$ & \multicolumn{2}{|c|}{14} & $\begin{array}{l}\text { Amplitude } \\
{[\mu \mathrm{m}]}\end{array}$ & & \multicolumn{2}{|c|}{20} \\
\hline $\begin{array}{c}\text { Rotations } n \\
{\left[\mathrm{~min}^{-1}\right]}\end{array}$ & 5200 & 5600 & $\begin{array}{l}\text { Rotations } \\
{\left[\min ^{-1}\right]}\end{array}$ & & 6000 & 7000 \\
\hline $\begin{array}{c}\text { Wavelength } L r \\
{[\mu \mathrm{m}]}\end{array}$ & 102 & 110 & $\begin{array}{l}\text { Wavelength } \\
{[\mu \mathrm{m}]}\end{array}$ & & 48 & 57 \\
\hline$\underset{[-]}{\text { Cycles }} \boldsymbol{N r}$ & 246 & 228 & Cycles & Nr [-] & 259 & 222 \\
\hline Angle & 15.313 & 14.265 & Angle & $\alpha / \%$ & 22.402 & 19.460 \\
\hline
\end{tabular}

According to the comparison of values of angle $\alpha$ and angle $\beta$, the influence of ultrasonic vibrations on edge-chipping is clear. The entry angle of the grit affects the spreading of the micro-cracks [6]. The higher the entries angle of the grit into the material, the deeper the cracks spreading, i.e. the higher the edge-chipping rate. That is the reason for higher edge-chipping depth in machining with ultrasonic vibration in comparison to the machining without the vibrations. The mechanical abrasion is the main mechanism of material removal in RUM, hence the effect of entry angle on edge-chipping is significant.

Measured values of edge-chipping according to machining technology and machining parameters are shown in Fig. 4 and Fig. 5 respectively. From figures, it is clear that the decrease of edge-chipping in milling is more significant than in drilling which corresponds with the theoretical assumption based on deduced equations.

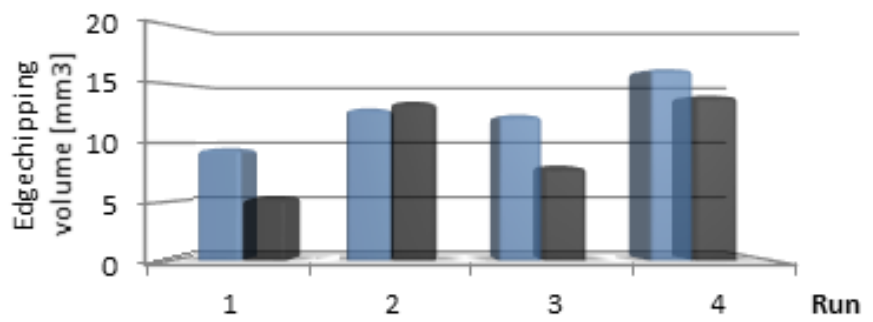

Fig. 4. Comparison of edge-chipping volume in drilling with (blue) and without ultrasound (grey).

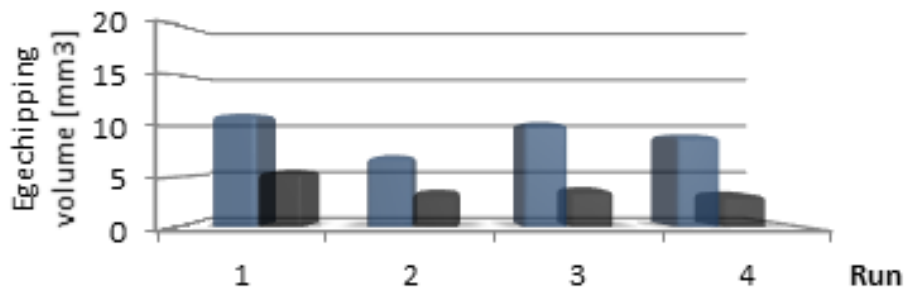

Fig. 5. Comparison of edge-chipping volume in milling with (blue) and without ultrasonic vibrations (grey).

\section{Conclusions}

The edge-chipping in rotary ultrasonic drilling and milling of $\mathrm{Al}_{2} \mathrm{O}_{3}$ ceramics depends on the kinematics of the machining process. The reason is the material removal mechanism of machining of brittle materials. The main mechanism is the brittle fracture [7-9]. The 
mechanism of brittle fracture is based on the micro-cracks initiation in material and their spreading into the material. The spreading of the cracks depends on the entry angle of the tool's grit into the material [10]. With a higher angle, the cracks are indented deeper into the material. When the tool vibrates, the grit trajectory differs from the grit trajectory without ultrasonic vibrations. Without ultrasonic vibrations, the entry angle is near $0^{\circ}$. In ultrasonic machining, the angle is increased in the order of tool vibration's frequency, amplitude, rotations and diameter. For tools used in experiments, the entry angle is from $15^{\circ}$ for a hollow drill to $20^{\circ}$ for end mill. Therefore the cracks initiation and spreading in oriented more into the material and the edge-chipping occurs earlier than in machining without vibrations. Therefore the edge-chipping depth is higher for machining with ultrasonic vibration.

The entry angle of grit also explains the higher edge-chipping decrease in milling with ultrasonic vibrations versus milling without ultrasonic vibrations in comparison to drilling. The entry angle for drilling is about $15^{\circ}$ and for milling from $19^{\circ}$ to $22^{\circ}$. Hence the decrease of edge-chipping in milling should be higher in order of turning off the ultrasonic vibrations than in drilling. The measured values of edge-chipping confirm this assumption. In drilling, the mean decrease of edge-chipping was $18 \%$ for depth and $34 \%$ for volume in the order of turning off the ultrasonic vibrations. In milling, the mean decrease of edgechipping was $55 \%$ for depth and $66.5 \%$ for volume i.e. the decrease of edge-chipping in milling in order of turning off the ultrasonic vibrations is greater.

The effect of vibrations on edge-chipping is proposed. From the conclusion written hereinbefore, the tool with ultrasonic vibration provides greater edge-chipping rate, and better results were obtained without the vibrations at the end of machining process where the tool is going out of the material. Results of this research could be implemented in cutting edge preparation of ceramic inserts.

The article was written with the support of the Project of VEGA grant agency of the Ministry of Education, Science, Research and Sport of the Slovak Republic and Slovak Academy of Sciences, no. 1/0097/17: "The research of novel method for cutting edge preparation to increase the tool performance in machining of difficult-to-machine materials" and APVV Project of Slovak Research and Development Agency of the Ministry of Education, Science, Research and Sport of the Slovak Republic, no. APVV-16-0057: "Research into the Unique Method for Treatment of Cutting Edge Microgeometry by Plasma Discharges in Electrolyte to Increase the Tool Life of Cutting Tools in Machining of Difficult-to-Machine Materials."

\section{References}

1. Z. Li. Kansas State University, http://krex.k-state.edu/dspace/handle/2097/198(2006).

2. Z.C. Li, L.-W. Cai, Z.J. Pei, C. IJMTM. 46, 12-13, (2006),

3. Q.H. Zhang, et al. JMPT. 84, 1-3, (1998)

4. N. Qin, Z.J. Pei. ASME. (2010)

5. J. Wang, P. Feng, J. Zhang, W. Cai, H. Shen. Ultrasonics. 74, (2017),

6. P.L. Ko, et al.. Wear 251, 1-12, (2001).

7. P.Auerkari. ESPOO: TRCF, (1996).

8. N. Chandra, G.C. Lim, H.Y. Zheng.. Ultrasonics. 52, 5, (2012),

9. Z.J. Pei, P.M. Ferreira, M. Haselkorn. JMPT. 48. 1-4, (1995)

10. M. Zvončan., Dissertation thesis, Trnava: Slovak University of Technology, (2012). 